\title{
Some Specific Features Of Foreign Language Legal Concept Formation In Perception Of Law Students
}

\author{
Enrique Quero Gervilla ${ }^{1}$, Lilia Moiseenko ${ }^{2}$, Maria Vikulina ${ }^{2 *}$, Tatyana Uskova $^{2}$ \\ ${ }^{1}$ University of Granada, Avenida del Hospicio, S/N C.P. 18010, Granada, Spain \\ ${ }^{2}$ Moscow State Linguistic University, 38, Ostozhenka St, Moscow, 119034, Russian Federation
}

\begin{abstract}
In the process of studying a foreign language a student develops a conceptual view of the world similar to that of a native speaker's. The structures of basic second language concepts formed in the process of education manifest certain differences from the concept structure in a native speaker's perception. Similarities in the perception of a legal concept nucleus in the mind of a foreign language student and a native speaker play an essential role in legal communication, since inaccuracy of perception and misunderstanding may result in negative legal consequences. The authors believe it is important to make a point of associative-verbal networks which include different foreign language legal terms and are fixed in the minds of students who study legal English and the Anglo-American legal system. The purpose of the study is to reveal how well associative-verbal links and structures of legal concepts have been formed in the minds of law students, who study legal English and the Anglo-American legal system, as well as to examine the principles according to which associates get fixed in their minds. As a research method the authors applied a free associative experiment, since this is the easiest way to establish links between ideas and concepts in an individual's mind.
\end{abstract}

\section{Introduction}

In the process of a foreign language studying a student develops a conceptual view of the world similar to that of a native speaker. The basic concept structures formed as the result of the second language studying have certain differences if compared with the native speaker's perception of the same concepts. Correlation of the legal concept nucleus in the minds of a second language student's and a native speaker's are especially essential, since the inaccuracy of perception may lead to negative legal consequences. The periphery of the student's legal concept is of particular interest, as it may allow to correct wrongly formed foreign language legal concepts.

Knowledge structuring in the process of second language acquisition as well as the organization and formation of the semantic space in the process of second language concepts importing have long been of great interest for researchers. Over the last years, attempts have been made to bring into correlation the level of the second language reference level and construction of associative-verbal networks in the second language, assessing not only the reaction words, but the stability/diversity and similarity/variety of associative models.

\footnotetext{
*Corresponding author: vikulina_maria@mail.ru
} 
The results of multiple researchers have shown that the higher level of the second language acquisition draws the verbal-associative networks nearer to those that exist in the native speaker's mind, i.e. to the patterns that demonstrate absence of variety and stability.

One of the most often used methods to establish associative links, defining their stability and assessment of how well the second language concepts have been formed is the associative experiment. In the course of the present research in order to assess how well the associativeverbal networks have been formed the respondents, Moscow State Linguistic University graduate students, were asked to provide their associations to three legal terms «justice», «law» and «jury», that enabled the researchers to determine the most frequent reactions and principles of consolidation of the associates on the basis of synonymy, antonymy and syntactical combinability.

\section{Associative Experiment as a Means of Associative-Verbal Links Reconstruction in a Second Language}

The term association is used in psycholinguistics and denotes a link or relationship between ideas, notions or words, that exist in a human mind, whereby emergence of one element causes emergence of another $[1 ; 2]$. G.A. Miller notes the recognition effect of associations, the respondents tend to offer faster associations to familiar stimulus words, or in situations when the stimulus words have been given to them before. [3].

Many researchers believe that the simplest experimental technique that enables to reveal associative mechanism is the free associative experiment (FAE) in the course of which respondents are offered a list of stimulus words (in oral or written forms) and asked to say the first idea that occurs to them. Thus the researchers obtain some data which provides some information about how knowledge is structured in a human's mind. The FAE results in which the respondents are offered hundreds and thousands of stimulus words are performed in a form of a table and are called Word Association Norms (WAN) or Word Association Thesaurus (WAT) depending on the number of associations [1;2].

Some researchers, for instance I. Istifci, H. Kruse, B. Wolter

And others in the course of the FAE made an attempt to establish a link between the language reference level and the responses to the stimulus words. They claimed that the association thesaurus could become a means of assessment of the language reference level. $[4 ; 5 ; 6]$. However, later on the results of these studied were criticized.

B. Wolter's research [6] revealed that associations to foreign words offered by second language students, non-native speakers do not depend on the language reference level. J. Read's study [7] was devoted to studying how well English language students knew the "academic words". Read's test consisted of a stimulus word followed by eight more words the four of which were semantically linked with it while the other four were not. J. Read aimed at assessing the respondents' knowledge of the meaning of the word, the lexemes it is associated with and collocations it is used in. J. Read allocated tree types of associations:

a. pragmatic (the two words are synonyms or at least have a similar meaning, one may have a more general meaning than the other);

b. syntagmatic (the two words are the elements that often occur in a sentence);

c. an association that reflects or illustrates one aspect or component of the stimulus word and as the result can act as a part of dictionary definition of the word [7, c. 359].

As the result of his research J. Read came to a conclusion that native speakers have surprisingly stable patterns of associations which may indicate complex lexical and semantic links developed in the process of language acquisition. On the other hand, non-native speakers demonstrate more diverse and unstable associations, their answers are often based on phonological and not on semantic links with the stimulus words [7, c. 358]. 
As it was noted in the work of J. Richards [8], the data received in the course of the FAE provide information about psychological structuring of an individual's vocabulary that can be studied on the basis of syntactic and semantic relationships between the words.

\section{Associative-Verbal Links in the Field of Legal Communication (on the basis of an associative experiment)}

One hundred of Law faculty graduate students who studied legal English and the law systems of England and the USA took part in the free associative experiment. The respondents were asked to offer their associations in English to the following stimulus words «justice», «law» and «jury». The experiment aimed at establishing the existence of formed associative-verbal links in the second language in the field of law and assessing how well the students have acquired the second language legal concepts.

It should be noted that, on the one hand, the reactions offered by the respondents demonstrated variety of associative links, on the other hand, the majority of the experiment participants offered associations based on synonymy.

So, as a reaction to the stimulus word justice $14 \%$ of the respondents offered synonymous words fairness and equity. 10\% pointed out the aspects which in their mind justice must provide: equality, right, impartiality, peace.

The experiment allowed to establish that the associative-verbal network of the word justice of the students who studied legal English included the parties involved in the administration of justice, as well as the organs that fulfil this function: $18 \%$ of the respondents offered the reaction court, $14 \%$ made a connection between such notions as judge, lawyer, police/policeman. We assume that these associations are implemented in the student's mind due to the use of the discursive approach to teaching legal English as well as due to the frequent use of the word justice in the context of judicial process among other things as a synonym to the word judge.

From our point of view, it is interesting to note that in comparison with the previous associative experiment in the Russian language in which similar legal concepts were used, the associations to the English word justice revealed fewer negative reactions, $6 \%$.

Reactions based on antonymy and combinability of lexical units were offered in $2 \%$ of the responses: injustice $-1 \%$, to do $-1 \%$.

Substantially higher number of reactions based on set phrases were offered to the stimulus word law: to obey, to study, to breach $-12 \%$. There were no antonyms offered, however, reactions based on synonymy made $18 \%$ of the responses: rules, statute. Six per cent of the respondents provided the names of certain branches of law, while six more percent pointed at its material form: code, book constitution.

Another fact worth mentioning is that among reactions of the students, who studied legal English, were associations directly connected with the educational process to study and faculty. These reactions are not frequent and connected, in our opinion, with the situation of acquisition of the English language legal concepts. Be tend to believe that this aspect of the concept law is mainly caused by the perception based in the process of the second language acquisition and will exist in the periphery of the abovementioned concept of the non-native speaker.

The participants of the process of legal communication (attorney, judge, government) were also represented as reactions, however, they were rather infrequent only $3 \%$ of the responses.

The most frequent reactions to the stimulus word jury were divided into three main categories: associations connected with the judicial process (court, trial, bench) - 40\%; associations connected with the composition of the jury (twelve, people, lay, men) - 10\%; characteristics associated with the jurors (fair, just, impartial, angry) $-12 \%$. The previously held associative experiment in the Russian language with the use of similar concepts did not reveal stable associative links between the words trial and jury. On these grounds be believe 
that the fact that in the English language the students demonstrated a firm link between the English word jury and lexemes verbalizing different aspects of judicial process has been influenced by the jury trial popularity in the Anglo-American legal system and frequency of addressing to this procedure in the process of legal English studying as well as studying of the United Kingdom and the USA legal systems.

\section{Conclusion}

Thus we assume we can make the following conclusions:

1. In the process of studying a second legal language and the legal system of the target-country country legal system due to imitation of realities of legal sphere for the non-native speaker the student demonstrates formation of second language legal concepts.

2. The process of formation of second language legal concepts is accompanied by construction of stable associative links between legal notions, mostly on the basis of synonymy.

3. The discursive approach to teaching provides opportunities to form in the student's mind the image of the native speaker's professional world view and bring the associative-verbal network in the field of professional of the student as close as possible to the associativeverbal network of the native speaker.

The results of the present research can be used in the bigger research projects in order to reveal regularities in formation of associative-verbal links between legal terms in Russian and English, as well as for correcting legal concepts formed in the second language with the aim at successful legal communication.

\section{Acknowledgments}

This work was supported by the Russian Foundation for Basic Research, grant No. 20-01200466

This paper was financially supported by the Russian Foundation for Basic Research, grant No. 20-012-22046

\section{References}

1. A. Sinopalnikova, Word Association Thesaurus as a Resource for Building WordNet, in P.Sojka, K. Pala, P. Smrz, C. Fellbaum, P. Vossen (Eds.): GWC 2004, Proceedings, pp. 199 - 205, Masaryk University, Brno (2003). pp. 199-205.

2. I.V Azarova., O.A. Mitrofanova, A.A Sinopalnikova, Computer tesaurus of the Russian language "WordNet". Retrieved from: http://www.interface.ru/iarticle/files/36208_70277329.pdf) (Access: 06.09.2020) (in Russ.)

3. G. A Miller, The Science of Words, New York: Scientific American Library (1996)

4. I. Istifci, Playing with Words: A Study on Word Association Responses (2010). Retrieved from:

https://www.researchgate.net/publication/42637325_playing_with_words_a_study_on_w ord_association_responses (Access: 06.09.2020)

5. H. Kruse, J. Pankhurst, M.S. Smith, A multiple Word Association Probe in Second Language, Cambridge University Press (2008). Retrieved from: https://doi.org/10.1017/S0272263100000449 (Access: 06.09.2020) 
6. B. Wolter, Assessing proficiency through word associations: is there still hope? System, Vol. 30, pp.315-329 (2002)

7. J. Read, The development of a new measure of L2 vocabulary knowledge. Language Testing, 10, pp. 355-371 (1993)

8. J. C. Richards, The Context of Language Teaching, Cambridge: CUP, (1991)

9. M. Bahar, M.H. Hansell, The relationship between some psychological factors and their effect on the performance of grid questions and word association tests. Educational Psychology, Vol. 20, No. 3 (2000) 